\title{
Anesthesia Management of Total Thyroidectomy Using a NIM EMG Endotracheal Tube: A Case Report
}

Toi Nei Chan*

Texas Christian University School of Nurse Anesthesia, USA

*Corresponding author: Toi Nei Chan, Texas Christian University School of Nurse Anesthesia, USA, E-mail: t.chancortes@tcu.edu

Received date: April 07, 2016; Accessed date: April 27, 2016; Published date: April 29, 2016

Copyright: (C) 2016 Chan TN. This is an open-access article distributed under the terms of the Creative Commons Attribution License, which permits unrestricted use, distribution, and reproduction in any medium, provided the original author and source are credited.

\begin{abstract}
Total thyroidectomy is not routinely performed for indications other than malignancy until the last quarter of the twentieth century. Despite significant advancement in surgical techniques of total thyroidectomy developed by Theodore Kocher and William Halsted, significant risks including damage to the recurrent laryngeal nerve, hematoma, and thyroid storm are still important considerations when weighing against surgical benefits. Currently the use of neural integrity monitor (NIM) electromyogram (EMG) tracheal tube has become increasingly popular among surgeons to reduce risks of damage to the recurrent laryngeal nerves. The purpose of this case report is to discuss anesthetic management in a 48-year-old female patient undergoing total thyroidectomy using a NIM endotracheal tube (Medtronic Xomed, Jacksonville, Florida).
\end{abstract}

Keywords: Anesthesia; Hyperextension; Extubation

\section{Case Report}

A 48-year-old female, $173 \mathrm{~cm}, 79 \mathrm{~kg}$, was admitted for total thyroidectomy. The patient was diagnosed with benign multinodular goiter 2 months ago and had since elected to undergo total thyroidectomy. There was no underlying comorbidity identified during physical assessment. Airway assessment revealed Mallampati classification II, thyromental distance greater than 3 fingerbreadths, and full range of motion in the neck. Surgical history included ablation of the uterus. The patient had no reported drug allergies. Medications included multi-vitamin supplements. Base line vital signs were blood pressure (BP), 135/70 $\mathrm{mmHg}$; pulse, $70 / \mathrm{min}$; respirations, $17 / \mathrm{min}$; $\mathrm{SpO}_{2} 99 \%$; and temperature $36.1^{\circ} \mathrm{C}$. Preoperative laboratory values were all within normal defined range.

In preoperative holding unit, an 18-gauge intravenous (IV) catheter was inserted in the left hand; an infusion of $0.9 \%$ normal saline solutions was started. The patient reported nothing by mouth for 10 hours prior, and midazolam $2 \mathrm{mg}$ IV was given prior to transferring to the operative room. Upon arriving to the operating room, the patient was preoxygenated for 5 minutes and standard monitors were attached. Pre-induction vital signs were: BP, $132 / 79 \mathrm{mmHg}$; pulse, $82 / \mathrm{min}$; respirations, $22 / \mathrm{min}$; and $\mathrm{SpO}_{2} 100 \%$. Induction began with injection of diprivan $200 \mathrm{mg} \mathrm{IV}$, fentanyl $100 \mu \mathrm{g} \mathrm{IV}$, defasciculating dose of rocuronium $5 \mathrm{mg} \mathrm{IV}$, succinylcholine $120 \mathrm{mg} \mathrm{IV}$, and lidocaine $100 \mathrm{mg}$ IV. The eyes were taped. A 7.0-mm NIM endotracheal tube (Medtronic Xomed, Jacksonville, Florida) was inserted in the trachea with the silver color-coded contact band appropriately placed between the vocal cords under direct laryngoscopy. End-tidal carbon dioxide $\left(\mathrm{EtCO}_{2}\right)$ was detected, and bilateral chest breaths sounds were present. The patient was then placed under volume control ventilation mode. Ventilator settings were: tidal volume, $600 \mathrm{~mL}$; respirations, 10 breaths per minute; I:E ratio, 1:2; and PEEP at $5 \mathrm{~cm} \mathrm{H}_{2} \mathrm{O}$. Post induction vital signs were $\mathrm{BP}, 117 / 66 \mathrm{mmHg}$; pulse, $86 / \mathrm{min}$; $\mathrm{SpO}_{2}, 100 \%$; and $\mathrm{EtCO}_{2}$, $34 \mathrm{mmHg}$.
General anesthesia was maintained under $1 \mathrm{~L}$ oxygen, $1 \mathrm{~L}$ of air, and $3 \%$ sevoflurane. An oroesophageal temperature probe was inserted. The patient was then repositioned in supine position with arms tucked in the neutral position on both sides. A soft shoulder roll was placed to maximize exposure of the neck. The head of the bed was elevated to $30^{\circ} \mathrm{C}$. A lower body warming blanket was used. Eye protective goggles were placed to avoid accidental compression during the surgery. Dexamethasone $10 \mathrm{mg}$ and fentanyl $100 \mu \mathrm{g}$ IV were given immediately prior to incision. Continuous EMG was monitored throughout the case by technician at the bedside. The patient BP dropped to 79/54 five minutes after incision, phenylephrine $50 \mu \mathrm{g}$ IV was administered. Blood pressure increased to $105 / 58$.

Hemodynamics remained stable throughout the case. Fentanyl 25 $\mu \mathrm{g} I V$ was given after returning of spontaneous ventilations during. The function of recurrent laryngeal nerves was assessed using EMG prior to extubation. Endotracheal tube was removed after criteria for awake-extubation had been achieved. The patient was transferred and the immediate postoperative vital signs were BP, $153 / 75$; pulse, $84 / \mathrm{min}$; $\mathrm{SpO}_{2} 100 \%$, respirations, $13 / \mathrm{min}$; temperature, $36.9^{\circ} \mathrm{C}$. Discharge home instructions were generated.

\section{Discussion}

Subtotal thyroidectomy has been historically the preferred surgical intervention for management of benign thyroid disorders due to lower risks of inflicting permanent damage to the recurrent laryngeal nerve and causing hypothyroidism. However, subtotal thyroidectomy is associated with higher rates of recurrence (30\% and $50 \%$ ) compare to total thyroidectomy [1,2]. Moreover, there is always a chance for some nodules to be left behind following subtotal thyroidectomy [2]. With the introduction of NIM EMG tracheal tube (Medtronic Xomed) and hormone replacement therapy, total thyroidectomy has extended its indications for successful management of thyroid disorders other than malignancy. NIM-aided intraoperative dissection was able to successfully identify the external branch of superior laryngeal nerve (EBSLN) in $97.2 \%$ (95\% confidence interval [CI], 95.5-98.9) of the cases compared to $87.5 \%(95 \% \mathrm{CI}, 82.1-89.3)$ in traditional surgical 
dissection alone [3]. The use of NIM EMG endotracheal tube is not without its risks. Malpositioning of endotracheal tube during induction and maintenance can inadvertently disrupt intraoperative neuromonitoring, resulting in increased risk of damage to the recurrent laryngeal nerves [4].

To optimize intubation condition, the patient should remain supine with head and neck in neutral position. Succinylcholine $1-1.5 \mathrm{mg} / \mathrm{kg}$ can be administered to facilitate intubation. No additional muscle relaxation is routinely required for remainder of the case [5]. The tube should be advanced between vocal cords with the exposed electrodes in contact of the patient's vocal cords in order to generate an accurate electromyogram after the electrodes are connected to the multichannel EMG monitoring device [5]. Lidocaine 2\% gel is not recommended as it can disrupt EMG readings. The patient should then be repositioned with the head elevated 30 degrees and the neck extended by placing a soft shoulder roll underneath [4]. Hyperextension of the patient's neck should be avoided [4]. After the patient is repositioned, proper placement of endotracheal tube should again be verified using the EMG. The electric current should be set at $0.5 \mathrm{~mA}$ (the lowest recommended current to elicit EMG signals) initially and advanced to $0.8 \mathrm{~mA}$ until a continuous EMG can be generated [4]. The depth of endotracheal tube should be measured $20.6 \pm 0.97 \mathrm{~cm}$ at lip in men, and $19.6 \pm 1.0 \mathrm{~cm}$ at lip in women [4]. Eye lubrications and goggles are recommended due to limited visualization of the face after sterile drapes are applied [5].

Total thyroidectomy is performed using Kocher approach by making a transverse neck incision of $6-8 \mathrm{~cm}$ long [5]. Hemodynamic monitoring during the procedure is paramount; should hypotension occur during surgery, the patient is effectively treated with direct acting vasopressor such as phenylephrine. The use of ephedrine should be limited to persistent hypotension accompanied by bradycardia as it increases the release of catecholamines [5]. The use of preoperative $\beta$ blockers is recommended for patients experiencing hyperthyroidism as they can effectively suppress adrenergic receptors [5]. In this particular case study, the patient did not take $\beta$-blockers because there was no evidence of hyperthyroidism identified.

Total thyroidectomy can also be performed under local/regional anesthesia via intravenous sedation accompanied by bilateral cervical blocks [6]. In preoperative area, local anesthetics are infiltrated through anterior rami of $\mathrm{C} 2-\mathrm{C} 4$ [6]. An ultrasound guided local anesthetic injection method is recommended. Transient paralysis to the recurrent laryngeal nerves can become an airway recovery when bilateral cervical blocks are placed [6]. After injection of cervical block on one side, it is important to assess the patient's ability to phonate before proceeding to the contralateral side [6]. Local anesthesia is associated with superior patient outcomes compared to general anesthesia [6]. Some of the advantages including less bleeding, shorter hospital stay, lower incidence of postoperative nausea and vomiting, and reduced costs have been reported Despite all the mentioned advantages, local/regional anesthesia for total thyroidectomy is still a less popular alternative among surgeons and patients in the United States

The recommended extubation technique in patients undergoing total thyroidectomy is awake extubation. The ability of the patient to support his/her own ventilations and maintenance of a secured airway is paramount in managing anesthesia care for thyroid surgeries $[2,4,5]$. Excessive bucking and coughing should be avoided during recovery.

As it can lead to hematoma formation at the surgical site [5]. The use of a short acting opioid such as fentanyl or remifentanil has been reported to reduce coughing and bucking during recovery [7].

\section{References}

1. Gough IR, Wilkinson D (2000) Total thyroidectomy for management of thyroid disease. World J Surg 24: 9622-9965.

2. Serpell JW, Phan D (2007) Safety of total thyroidectomy. ANZ J Surg pp: 15-19.

3. Glover AR, Norlen O, Gundara JS, Morris M, Sidhu SB (2015) Use of the nerve integrity monitor during thyroid surgery aids identification of the external branch of the superior laryngeal nerve. Ann Surg Oncol 22: 1768-1773.

4. Lu IC, Chu KS, Tsai CJ, Wu CW, Kuo WR, et al. (2008) Optimal depth of NIM EMG endotracheal tube for intraoperative neuromonitoring of the recurrent laryngeal nerve during thyroidectomy. World J Surg 32: 1935-1939.

5. Elisha S, Boytim M, Bordi S, Heiner J, Nagelhout J, et al. (2010) Anesthesia case management for thyroidectomy. AANA J 78: 151-160.

6. Milan SA, Wu LS, Sosa JA (2014) Thyroidectomy under local anesthesia. Curr Surg Rep 2: 37.

7. Yoo YC, Jeong JJ, Choi EM, Moon BE, Lee JR (2011) Dose-dependent attenuation by fentanyl on cough during emergence from general anesthesia. Acta Anaesthesiol Scand 55: 1215-1220. 